\title{
CONTROLE MICROBIOLÓGICO DA VIDA DE PRATELEIRA DE RICOTA CREMOSA
}

\author{
Microbiological assessment of creamy ricota during shelf-life
}

\author{
Ana Cristina Ribeiro ${ }^{1}$, Simone Cristina Marques ${ }^{2}$, Arthur de Freitas Sodré ${ }^{3}$ \\ Luiz Ronaldo de Abreu ${ }^{4}$, Roberta Hilsdorf Piccoli $^{5}$
}

\begin{abstract}
RESUMO
Desenvolveu-se este estudo com a finalidade de verificar alguns microrganismos indicadores de contaminação e deterioradores em ricota cremosa durante sua vida de prateleira. No controle microbiológico do produto observaram-se os seguintes resultados: $<0,3 \mathrm{NMP} / \mathrm{g}$ de coliformes, $<1,0 \times 10^{2} \mathrm{UFC} / \mathrm{g}$ de Staphylococcus produtores de coagulase e contagem total de aeróbios mesófilos entre 2,0 x $10^{2}$ e 2,45 x $10^{4} \mathrm{UFC} / \mathrm{g}$. As contagens de aeróbios mesófilos diminuíram com o tempo de armazenamento, já que as amostras foram mantidas durante vinte dias sob temperatura de geladeira $\left(7^{\circ} \mathrm{C}\right)$. Os resultados do controle microbiológico da ricota cremosa demonstraram condições higiênico-sanitárias satisfatórias.
\end{abstract}

Termos para indexação: ricota, análise microbiológica

\begin{abstract}
The occurrence of spoiler microrganisms in creamy ricotta during its shelf-life was assessed. The results showed the following contamination levels: $<0.3 \mathrm{MPN} / \mathrm{g}$ of coliforms, $<1.0 \times 10^{2} \mathrm{CFU} / \mathrm{g}$ of coagulase producing Staphylococcus and total aerobic mesofilic counts of between $2.0 \times 10^{2}$ and $2.45 \times 10^{4} \mathrm{CFU} / \mathrm{g}$. The aerobic mesofilic counts decreased with storage time, with the samples being kept during twenty days under refrigerating condition $\left(7^{\circ} \mathrm{C}\right)$. The results of creamy ricotta microbiological assessment showed satisfactory hygienical-sanitary conditions.
\end{abstract}

Index terms: ricotta, microbiological analysis

(Recebido para publicação em 04 de dezembro de 2002 e aprovado em 19 de outubro de 2004)

\section{INTRODUÇÃO}

A demanda cada vez mais crescente dos consumidores por alimentos convenientes, frescos, naturais, semiprocessados e com menor quantidade de conservantes e aditivos, muitas vezes resulta na obtenção de produtos com reduzida vida de prateleira.

Pelo seu baixo teor de gordura, alta digestibilidade e ausência de sal, a ricota é considerada um produto leve e dietético, mundialmente consumido em muitas dietas alimentares. Nos últimos 5 anos, o produto aumentou sua produção em cerca de 35\%, números referentes a estabelecimentos sob inspeção federal (ABIQ, 2001).

A ricota é um queijo de origem italiana fabricado em diversos países sob várias denominações. É conhecida também por queijo de albumina, por se constituir basicamente desta e de lactoglobulina, que são os principais componentes protéicos do soro, não coaguláveis pelo coalho. São proteínas facilmente desnaturadas e precipitadas pelo calor, sob a influência de acidificação, o que constitui o princípio básico da fabricação da ricota (Furtado, 1994). Em outras palavras, a massa da ricota é obtida por meio da acidificação do soro de queijo, adicionado ou não de $10 \%$ de leite integral, após seu aquecimento a aproximadamente $92^{\circ} \mathrm{C}$. O rendimento médio da fabricação é de cerca de 4 a $6 \%$, sendo um produto de pouca durabilidade, e portanto, considerado queijo fresco. Geralmente, pode ser comercializada de várias formas: defumada, condimentada ou cremosa, na forma prensada ou em potes.

As exigências de mercado em relação a produtos mais nutritivos e saudáveis, particularmente no que se refere ao teor de gordura, estimulam a produção e criação de novos produtos como a ricota cremosa, com consistência de patê, porém, sem adição de creme de leite. Com isso, o produto final contém apenas proteínas de fácil digestão e alto valor biológico.

1. Médica Veterinária, Mestre em Ciência dos Alimentos, Universidade Federal de Lavras/UFLA - Caixa Postal 3037 - $37200-000$ - Lavras, MG.

2. Bióloga, Mestranda em Ciência dos Alimentos - UFLA

3. Aluno de Graduação do Curso de Zootecnia - UFLA.

4. Professor Titular, Departamento de Ciência dos Alimentos - UFLA.

5. Professor Adjunto, Departamento de Ciência dos Alimentos - UFLA. 
O processo de fabricação da ricota cremosa é bem semelhante ao da ricota comum, diferindo apenas quanto à temperatura utilizada e ao uso do vapor direto. A ricota cremosa é menos dessorada, o que se reflete na sua consistência e rendimento; entretanto, por ser um produto de muito alta umidade, torna-se mais propensa a deterioração, o que reduz sua vida de prateleira para apenas 1 a 2 semanas; já a ricota prensada encontrada facilmente no mercado possui prazo de validade de 30 a 60 dias.

A elevação da temperatura do soro ou mistura favorece a obtenção de uma massa com baixa contagem microbiana. Contudo, após sua obtenção, essa massa fica exposta a inúmeros pontos de contaminação, principalmente por ser excessivamente manipulada.

Devido à globalização, à entrada do Brasil no Mercosul e ao Código de Defesa do Consumidor, os cuidados e as preocupações referentes à qualidade microbiológica dos alimentos têm aumentado, principalmente para atenderem às exigências do mercado, de consumidores mais conscientes e dos órgãos de fiscalização com o intuito de evitar problemas de saúde pública. Porém, somente algumas empresas estão implantando sistemas mais eficazes de controle de qualidade do tipo APPCC (Análise de Perigos e Pontos Críticos de Controle) e BPF ou GMP (Boas Práticas de Fabricação), sendo que, nas demais, o controle ainda é incipiente ou quase inexistente, cabendo à população e aos órgãos de fiscalização a exigência de melhores condições higiênico-sanitárias dos produtos.

Desenvolveu-se este estudo com a finalidade de analisar alguns microrganismos indicadores de contaminação e deterioradores em ricota cremosa durante sua vida de prateleira, contribuindo, deste modo, com informações que poderão auxiliar os órgãos de saúde pública para um melhor controle de qualidade do produto.

\section{MATERIAL E MÉTODOS}

\section{Fabricação da ricota cremosa}

A produção foi realizada no laticínio da Cooperativa Agrícola Alto Rio Grande (CAARG), Lavras-MG, tomando-se os devidos cuidados higiênico-sanitários: o uso de luvas, máscaras, gorro e uniformes, entre outros.

O soro fresco proveniente da fabricação de queijo mussarela foi colocado em um tanque com aquecimento por meio de vapor direto, onde, então, ocorreu a redução da acidez original (situada entre $11^{\circ} \mathrm{D}$ e $14^{\circ} \mathrm{D}$ ) para $8{ }^{\circ} \mathrm{D}$, utilizando-se $\mathrm{NaOH}$. Logo após, iniciou-se o aquecimento (Figura 1).
$\mathrm{O}$ aquecimento foi feito até atingir a temperatura de $92{ }^{\circ} \mathrm{C}$, quando então realizou-se a acidificação com ácido lático 85\%. Para $100 \mathrm{~L}$ de soro utilizaram-se 100 $\mathrm{mL}$ de ácido lático, previamente diluído na proporção de 1:10 em água. $\mathrm{O}$ aquecimento foi interrompido por volta de $96{ }^{\circ} \mathrm{C}$, esperando o tempo necessário para que a massa aflorasse à superfície do soro e procedeu-se à coleta utilizando dessoradores, já que, com o uso desta técnica, os flocos são mais finos, o que propicia a consistência cremosa do produto sem que seja necessária a adição de creme. A ricota cremosa foi acondicionada em potes plásticos de 100 g, previamente esterilizados em luz ultravioleta (UV), os quais foram imediatamente transferidos para o Laboratório de Microbiologia de Alimentos do Departamento de Ciência dos Alimentos da Universidade Federal de Lavras, em prazo não superior a 1 hora.

\section{Controle Microbiológico}

A ricota foi homogeneizada e, então, submetida às análises microbiológicas de coliformes totais e fecais, estafilococos produtores de coagulase e contagem de aeróbios mesófilos, segundo a metodologia do ICMSF (1992). As amostras foram mantidas à temperatura de 7 ${ }^{\circ} \mathrm{C}$ e as análises foram realizadas nos tempos $0,7,14 \mathrm{e}$ 20 dias de estocagem.

\section{Preparo da amostra}

Pesaram-se $10 \mathrm{~g}$ da ricota cremosa em $90 \mathrm{~mL}$ de citrato de sódio a $2 \%$ e o material foi homogeneizado por agitação manual, já que a massa da ricota cremosa é bem fina, não necessitando ser triturada ou batida em liquidificador.

Foram então preparadas diluições seriadas até 1/1000 em porções de $9 \mathrm{~mL}$ de água peptonada a $0,1 \%$ $(\mathrm{p} / \mathrm{v})$, para o procedimento das determinações bacteriológicas.

\section{Determinação do Número Mais Provável (NMP/g) de coliformes fecais}

Utilizou-se o método de fermentação de lactose em tubos múltiplos, em que foi inoculado $1 \mathrm{~mL}$ das diluições $1 / 10,1 / 100$ e 1/1000, em três séries de três tubos contendo caldo lauril sulfato triptose, LST.

Após a incubação a $35^{\circ} \mathrm{C}$ durante 48 horas, o número de tubos presuntivamente positivos, que evidenciassem turvação e produção de gases nos tubos de Duhram, eram submetidos a uma tabela de NMP para 
determinação dos resultados expressos em NMP de coliformes totais/g de amostra analisada.

\section{Enumeração de estafilococos produtores de coagulase}

Inoculou-se com o auxílio de alça de Drigalski, sobre superfície de ágar de Baird-Parker, 0,1mL das diluições 1/10, 1/100 e 1/1000. Foram feitas duplicatas das placas para cada diluição. Após completa incorporação, as placas foram incubadas invertidas a $37^{\circ} \mathrm{C}$ durante 48 horas. Decorrido o período de incubação, procedeuse a contagem das placas e os resultados foram expressos em UFC/g. A confirmação da cepa como Staphylococcus aureus foi feita utilizando-se os testes de coagulase e termonuclease.

\section{Enumeração de microrganismos aeróbios me- sófilos}

Foram inoculadas em placas de Petri estéreis, utilizando-se a técnica de plaqueamento em profundidade, as di- luições 1/10, 1/100 e 1/1000. O meio utilizado foi o Ágar Padrão para Contagem (PCA). Foram feitas duplicatas das placas para cada diluição. As placas foram incubadas invertidas a $35{ }^{\circ} \mathrm{C}$ por 48 horas; após esse período, procedeu-se a contagem das colônias para convertê-las em UFC/g.

\section{Determinação de coliformes a $35^{\circ} \mathrm{C}$ e termo- tolerantes}

Coliformes termotolerantes foram quantificados utilizando-se a técnica do Número Mais Provável com séries de três tubos. Alíquotas de $1 \mathrm{ml}$ das diluições das amostras foram inoculadas em tubos contendo Caldo Lauril Sulfato Triptose e tubos de Durhan e incubados a $35^{\circ} \mathrm{C}$ por 48 horas. Dos tubos positivos para coliformes a $35^{\circ} \mathrm{C}$, realizaram-se repicagens da cultura, com o auxílio da alça de repicagem, para tubos contendo Caldo Escherichia coli (EC). Esses tubos foram incubados a $44,5^{\circ} \mathrm{C}$ por 48 horas, determinando-se o número mais provável de coliformes termotolerantes .

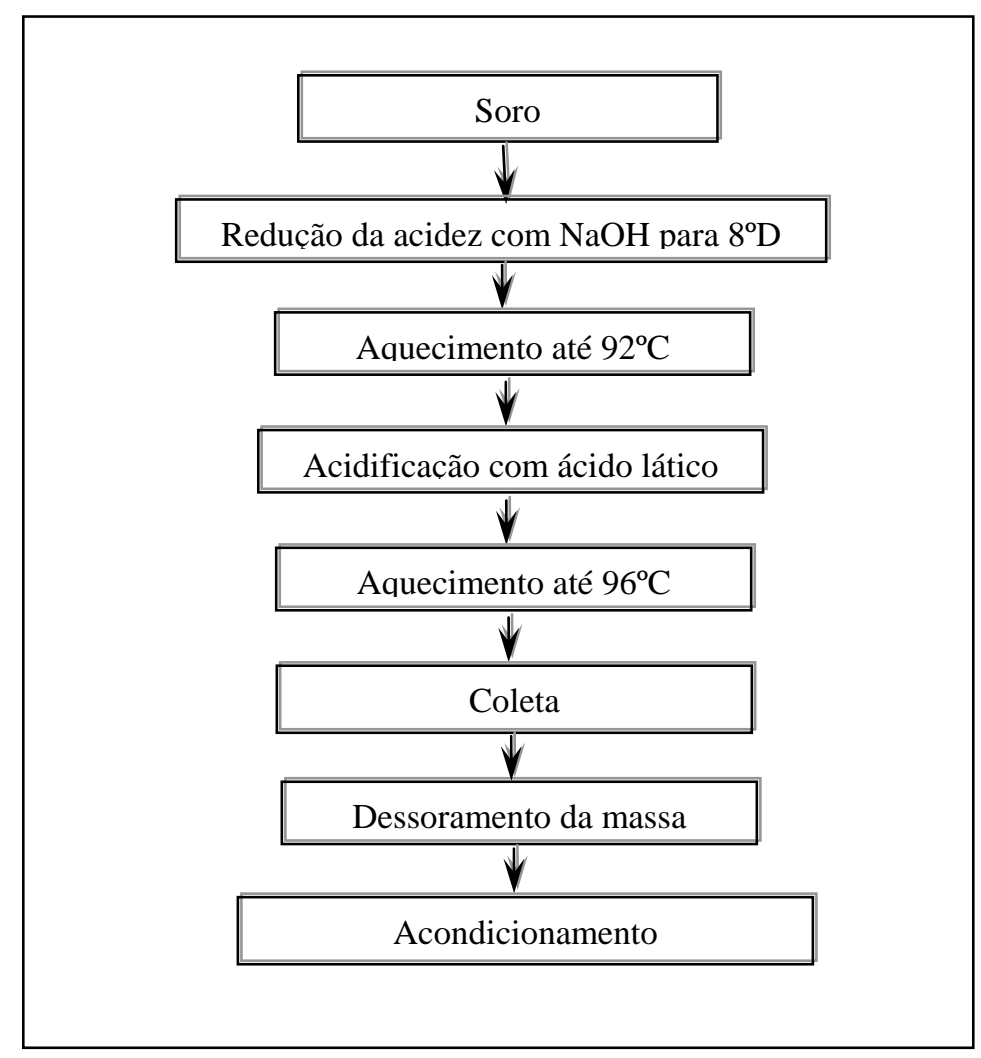

Figura 1 - Fluxograma de fabricação da ricota cremosa.

Ciênc. agrotec., Lavras, v. 29, n. 1, p. 113-117, jan./fev. 2005 


\section{RESULTADOS E DISCUSSÃO}

No Quadro 1 estão expressos os resultados de $\mathrm{NMP} / \mathrm{g}$ de coliformes totais e fecais, UFC/g de Staphylococcus produtores de coagulase e a contagem total de aeróbios mesófilos.

$\mathrm{Na}$ análise de coliformes totais e fecais foram encontrados valores $<0,3 \mathrm{NMP} / \mathrm{g}$ em $100 \%$ das amostras, isto é, em todos os períodos de estocagem analisados, o que está de acordo com a legislação (BRASIL, 2001). Silveira et al. (2000) analisando 5 marcas diferentes de ricota comum comercializadas em Lavras-MG, constataram que apenas uma delas estava de acordo com a legislação e as demais apresentaram valores médios de $3,3 \times 10^{5} \mathrm{NMP} / \mathrm{g}$ de coliformes totais e fecais. Em outro estudo sobre as características microbiológicas de ricota comum, Sakate et al. (1999) observou que $75 \%$ das 20 amostras analisadas continham < 100 $\mathrm{NMP} / \mathrm{g}$ de coliformes totais e fecais, sendo consideradas "produto aceitável para consumo quanto à análise microbiológica"; 15\% situavam-se entre 100 e 500 $\mathrm{NMP} / \mathrm{g}$, classificadas como "condições higiênicas do produto insatisfatórias", e 10\% apresentaram teor maior que $500 \mathrm{NMP} / \mathrm{g}$ de coliformes, estando "impróprias para consumo”. Essas últimas amostras eram provenientes de estabelecimentos sem inspeção sanitária, o que demonstra a importância da inspeção na qualidade dos alimentos.
Em relação ao grupo estafilococos, os resultados foram inferiores a $1,0 \times 10^{2} \mathrm{UFC} / \mathrm{g}$ em todas as amostras, valor compatível com aquele estabelecido por lei (BRASIL, 2001). Outros experimentos detectaram, em cinco marcas analisadas, resultados variando entre $9,5 \times 10^{3} \mathrm{e}$ $3,0 \times 10^{5} \mathrm{UFC} / \mathrm{g}$ de Staphylococcus spp. (SILVEIRA et al., 2000), valor fora do padrão vigente.

O microrganismo Staphylococcus aureus vem sendo, com freqüência, detectado em produtos de origem animal. Diversos são os relatos de literatura que citam a contaminação de queijos e leite com esse patógeno, sem contar os relatos de surtos de toxinose alimentar (PEREIRA et al., 1991; SABIONI, 1994; CARMO et al., 1996).

No que diz respeito à contagem total de microrganismos aeróbios mesófilos, sabe-se que é praticamente impossível obter contagens iguais a zero, tanto que em produtos considerados frescos não se exige padrão para este grupo de microrganismos. Ainda assim, esta análise foi realizada como controle da microbiota. Os resultados obtidos variaram de $2,0 \times 10^{2} \mathrm{UFC} / \mathrm{g}$ a $2,45 \times 10^{4} \mathrm{UFC} / \mathrm{g}$ de ricota cremosa. O baixo número de microrganismos encontrados, pode ser explicado pela alta temperatura utilizada no processamento e pelas condições de conservação. Pode-se observar no Quadro 1 , que a temperatura de estocagem, $7^{\circ} \mathrm{C}$, contribuiu para a redução destes microrganismos ao longo do tempo de armazenamento.

QUADRO 1 - Resultados do NMP/g de coliformes totais e fecais, UFC/g de Staphylococcus produtores de coagulase e a contagem total de aeróbios mesófilos, obtidos em ricota cremosa durante seu período de estocagem *

\begin{tabular}{|c|c|c|c|}
\hline $\begin{array}{c}\text { Tempo } \\
\text { (dias) }\end{array}$ & $\begin{array}{c}\text { Contagem Total de } \\
\text { Aeróbios Mesófilos } \\
\text { (UFC/g) }\end{array}$ & $\begin{array}{c}\text { NMP de Coliformes } \\
\text { Totais e Fecais } \\
\text { (NMP/g) }\end{array}$ & $\begin{array}{c}\text { Staphylococcus } \\
\text { produtores de coagulase } \\
\text { (UFC/g) }\end{array}$ \\
\hline 0 & $2,01 \times 10^{4}$ & $<0,3$ & $<1,0 \times 10^{2}$ \\
\hline 7 & $6,27 \times 10^{3}$ & $<0,3$ & $<1,0 \times 10^{2}$ \\
\hline 14 & $4,12 \times 10^{3}$ & $<0,3$ & $<1,0 \times 10^{2}$ \\
\hline 20 & $3,17 \times 10^{2}$ & $<0,3$ & $<1,0 \times 10^{2}$ \\
\hline
\end{tabular}

Dados referentes às médias obtidas das 3 repetições.

Ciênc. agrotec., Lavras, v. 29, n. 1, p. 113-117, jan./fev. 2005 


\section{CONCLUSÕES}

De acordo com a legislação, as amostras do produto analisado estão dentro dos padrões legais vigentes, ou seja, o produto apresenta condições sanitárias satisfatórias.

Todavia, os resultados obtidos neste experimento não descartam a necessidade de monitoração e controle de qualidade no processamento da ricota cremosa.

\section{REFERÊNCIAS BIBLIOGRÁFICAS}

ASSOCIAÇÃO BRASILEIRA DAS INDÚSTRIAS DE QUEIJO. Dados de produção Brasil em toneladas de produtos lácteos: 2000. São Paulo, 2001.

BRASIL. Ministério da Saúde. Secretaria Nacional de Vigilância Sanitária de Alimentos. Resolução $\mathbf{n}^{0}$ 12, de 2 de janeiro de 2001. Brasília, 2001.

CARMO, L. S. et al. Staphylococcus aureus and Salmonella enteritidis present in food implicated in food poisoning. Revista de Microbiologia, São Paulo, v. 27, p. 122-125, abr./jun. 1996.

FURTADO, M. M. Tecnologia de queijos: manual técnico para produção industrial de queijos. São Paulo: Pipemar, 1994. 118 p.
INTERNATIONAL COMMISSION MICROBIAL SPECIFICATION FOR FOODS. Microrganismos de los alimentos: técnicas de análises microbiológicas. 2. ed. Zaragoza: Acribia, 1992. 804 p.

PEREIRA, M. L. et al. Intoxicação por Staphylococcus aureus provocada por queijo "Tipo Minas". Revista de Microbiologia, São Paulo, v. 22, n. 4, p. 349-350, dez. 1991.

SABIONI, J. G. et al. Intoxicação estafilocócica causada por queijo tipo Minas em Ouro Preto (MG). Higiene Alimentar, São Paulo, v. 8, p. 22-23, 1994.

SAKATE, R. I.; SANTOS, F. L.; BRANDÃO, S. C. C. Características microbiológicas de ricota fresca comercializada no município de Belo Horizonte MG. Higiene Alimentar, São Paulo, v. 15, p. 22-23, 1999.

SILVEIRA, I. A. et al. Aspectos microbiológicos de ricotas comercializadas na região de Lavras- Minas Gerais: resultados parciais. In: CONGRESSO BRASILEIRO DE CIÊNCIA E TECNOLOGIA DE ALIMENTOS, 17., 2000, Fortaleza. Livros de Resumos... Fortaleza: [s.n.], 2000. v. 1, p. 1-4. 